\title{
Reproducibility between counts of airborne allergenic pollen from two cities in the East Midlands, UK.
}

Catherine H. Pashley ${ }^{1}$, Abbie Fairs ${ }^{1}$, Richard E. Edwards ${ }^{1}$, John P. Bailey ${ }^{2}$, Julie M. Corden ${ }^{3}$ and Andrew J. Wardlaw ${ }^{1}$

\author{
${ }^{1}$ Aerobiology Unit, Institute for Lung Health, Department of Infection, Immunity \& \\ Inflammation, University of Leicester, Leicester LE1 7RH \\ ${ }^{2}$ Department of Biology, University of Leicester, Leicester LE1 7RH \\ ${ }^{3}$ MAARA, No 1 Mill, The Wharf, Shardlow, Derby, DE72 2GH
}

Corresponding author: Catherine H Pashley; chp5@le.ac.uk tel (+44)116 2525078

\begin{abstract}
Historically in the East Midlands, UK, airborne pollen has been monitored in two cities, Derby and Leicester, situated 41 kilometres ( 25 miles) apart. The aim of the present study was to compare aerobiological data from both sites to determine if a forecast based on data from one site would be sufficient for both, and to address the wider issue of reproducibility between geographically separated sites.
\end{abstract}

Pollen types recorded could be split into two groups according to annual abundance, maximum daily concentration and the number of high count days. Six taxa made up the abundant group; ash, birch, grass, oak, nettle-type and yew-type, representing 90 and $88 \%$ of the total air spora for Derby and Leicester respectively.

Three consecutive years of grass and nettle pollen data are presented, supported by one year of abundant tree pollen data. There were highly significant positive correlations between the counts obtained. Line charts showing the average number of pollen grains $\mathrm{m}^{-3}$ air day ${ }^{-1}$ show similar trends, and Bland-Altman plots show little discrepancy between the amounts of pollen counted on any given day. Each day was classified according to the UK accepted threshold levels for grass. Weighted kappa statistics showed substantial or almost perfect agreement between the forecast classifications. With the caveat that this would not apply in a region with restrictions to air flow such as a mountain range, or with extreme fluctuations such as a coastline site, this study suggests that data from a single site is suitable for forecasting a distance of up to $41 \mathrm{~km}$.

Keywords Pollen forecast, hayfever, aerobiology, allergy 


\section{Reproducibility between counts of airborne allergenic pollen from two cities in the East Midlands, UK.}

\section{Abstract}

Historically in the East Midlands, UK, airborne pollen has been monitored in two cities, Derby and Leicester, situated 41 kilometres ( 25 miles) apart. The aim of the present study was to compare aerobiological data from both sites to determine if a forecast based on data from one site would be sufficient for both, and to address the wider issue of reproducibility between geographically separated sites.

Pollen types recorded could be split into two groups according to annual abundance, maximum daily concentration and the number of high count days. Six taxa made up the abundant group; ash, birch, grass, oak, nettle-type and yew-type, representing 90 and $88 \%$ of the total air spora for Derby and Leicester respectively.

Three consecutive years of grass and nettle pollen data are presented, supported by one year of abundant tree pollen data. There were highly significant positive correlations between the counts obtained. Line charts showing the average number of pollen grains $\mathrm{m}^{-3}$ air day ${ }^{-1}$ show similar trends, and Bland-Altman plots show little discrepancy between the amounts of pollen counted on any given day. Each day was classified according to the UK accepted threshold levels for grass. Weighted kappa statistics showed substantial or almost perfect agreement between the forecast classifications. With the caveat that this would not apply in a region with restrictions to air flow such as a mountain range, or with extreme fluctuations such as a coastline site, this study suggests that data from a single site is suitable for forecasting a distance of up to $41 \mathrm{~km}$.

\section{Introduction}

Research on atmospheric pollen began in the UK in 1941, with continuous trapping for extended periods at different sites having been carried out since 1942 (Hyde and Adams 1958). Trapping and recording airborne pollen has been useful in many different disciplines, including: monitoring climate change; estimating, detection or forecasting dispersal of allergens; risk assessment of GM pollen spread; and, cross-pollination of plant varieties (Lacey and West 2006).

Airborne pollen grains are an established cause of allergy related respiratory symptoms in predisposed subjects (Epton et al. 1997), being the primary cause of seasonal allergic rhinitis, and an important cause of asthma (Peternel et al. 2004, Taylor et al. 2007). In recent decades allergies due to pollen have greatly increased throughout the world, especially in large cities and industrialised areas (Peternel et al. 2004; Caiola et al. 2002; D'Amato et al. 2007). The three main types of allergenic pollen are grass, weed and tree pollen; however, not all species elicit strong allergenic effects ( D'Amato et al. 2007).

From a clinical perspective, pollen data can be a useful aid in diagnosing the cause of an individual's allergies. For an individual allergic to particular pollen, the prediction of the start of that pollen's season can allow them to adjust their daily activities so as to avoid contact with the allergen (Peternel et al. 2004), or to begin taking medication. Pollen count data is also important for research into allergic rhinitis, in particular for clinical trials into immunotherapy, vaccines and antihistamines, which rely on pollen counts to assess the efficacy of the drugs in relation to the severity of the allergenic stimulus (Keskin et al. 2006; Pajno et al. 2003; Mirone et al. 2004).

Historically in the East Midlands region of the UK, airborne pollen has been monitored at two cities, Derby and Leicester, situated forty-one km (twenty-five miles) apart. In April 2006 a new aerobiology unit was created to be responsible for counting and producing a forecast for both cities. Forecasts are produced daily or weekly based on the previous day or week's data, weather forecasts, and an understanding of pollen season trends. It takes time and effort to produce the counts and forecasts, so the aim of the present study was to compare aerobiological data from both cities obtained over a twelve month period, followed by two further years of summer grass and nettle pollen data, to determine if a forecast based on data from one site would be sufficient for both cities, and to address the wider issue of reproducibility between two geographically separated locations. 


\section{Materials and methods}

\subsection{Pollen Counting}

Atmospheric pollen was sampled over a twelve month period (April 2006 to 2007) using seven-day recording volumetric spore traps (Burkard manufacturing Co. Ltd) situated at the Universities of Leicester and Derby. After this period pollen was recorded for most of the year (apart from the winter months) for 2007 and 2008 at the Leicester site, and for the summer months at Derby. Derby (52 $55^{\prime}$ N $1^{\circ} 29^{\prime}$ W) is an industrial city with a population of about 230,000 , more than $100 \mathrm{~km}$ from any coast. The trap was sited on the roof of Derby University Mickleover site, $10 \mathrm{~m}$ above ground level in a suburb $110 \mathrm{~m}$ above sea level and approximately $4 \mathrm{~km} \mathrm{SW}$ of the city centre. Leicester $\left(52^{\circ} 38^{\prime} \mathrm{N} 1^{\circ} 5^{\prime} \mathrm{W}\right)$ is an industrial city with a population of about 280,000 , about $90 \mathrm{~km}$ from the coast. The trap was sited on the roof of a building on the University of Leicester campus, $12 \mathrm{~m}$ above ground level in an urban area $60 \mathrm{~m}$ above sea level and approximately $1 \mathrm{~km} \mathrm{~S}$ of the city centre. The two sites are $41 \mathrm{~km}$ (about 25 miles) apart.

Twenty-six pollen types were identified by pollen morphology microscopically according to British Aerobiology Federation standardised techniques (BAF 1995). Daily slide or seven day drum traps were used with mounting and staining techniques following methods described by Morrow Brown and Jackson (1978a). Pollen concentrations were expressed as average number of pollen grains per cubic metre of air per day (grains $\mathrm{m}^{-3}$ air day ${ }^{-1}$ ).

Minimum and maximum temperature and rainfall data were provided by meteorologist David Vince for Derby and the Leicester city council air quality group for Leicester, from meteorological stations $0.5 \mathrm{~km}$ and $5 \mathrm{~km}$ respectively from trap sites.

\subsection{Analysis}

Annual cumulative counts were calculated from the summation of daily average pollen concentrations. The six most abundant pollen taxa were then subjected to further analyses. Where appropriate, the $95 \%$ method was used to define the pollen season retrospectively, with the start of the season being the date on which $2.5 \%$ of the total count for the 12 months was recorded, and $97.5 \%$ being the end (Andersen 1991). When the 95\% method was not appropriate, start and end date were defined as per Fehér and Járai-Komlódi (1997).

A Wilcoxon signed rank test on the paired abundance data between the two cities was performed. Correlation between the Derby and Leicester pollen counts for each taxa and between temperature and rainfall variables were calculated using Spearman's rank correlation coefficient.

To compare the count obtained from both sites for any given day, pollen counts were normalised by log transformation using $\ln (\mathrm{Y}+1)$ where $\mathrm{Y}$ is the pollen count, then Bland-Altman plots were performed. The Bland-Altman plot looks at the difference between two measures of a specific pollen type on a single day. The mean value is plotted on the $x$-axis, and the difference between the actual values and the mean on the $y$ axis. If there was no difference between the counts on any given day all the data would be on the $y=0$ axis. Positive y values represent days when Derby counts are higher than Leicester, negative y values when Derby counts are lower. To check if the bias and variability are uniform throughout the range of measurement, the data is plotted graphically. The standard deviation of the differences is calculated to take into consideration variation about the mean, and the upper and lower confidence levels plotted. A Pearson product moment correlation of the difference versus average data is calculated to see if there is a consistent tendency for one site of measurement, to exceed the other (the bias).

Pollen levels on any given day were classified as low, moderate, high or very high based on accepted UK grass pollen threshold values (Smith and Emberlin 2005) and inter-site agreement was assessed using weighted kappa statistics using quadratic weighting. All analyses were performed using GraphPad Prism version 4.02 for Windows (GraphPad Software, San Diego California) with the exception of weighted kappa 
statistics for which MedCalc for Windows version 9.6.4.0 (MedCalc Software, Mariakerke, Belgium) was used.

\section{Results}

Pollen counts were recorded at both sites from 4th April 2006 to 4th April 2007 inclusive. In Derby 17 days were lost resulting in 349 days for comparison. In 2007 pollen counts continued to be recorded in Leicester until $11^{\text {th }}$ October, and in 2008 from $5^{\text {th }}$ February to $30^{\text {th }}$ September. Derby pollen counts were recorded in 2007 from $17^{\text {th }}$ May to $7^{\text {th }}$ September, and in 2008 from $4^{\text {th }}$ June 07 to $8^{\text {th }}$ September. Unless otherwise stated, results and discussion refer solely to the 4th April 2006 to 4th April 2007 study period.

A Wilcoxon signed rank test was performed on the paired annual abundance data (Table 1) for each pollen type and there was found to be no significant difference $(p=0.7215)$ between the two cities. The Spearman's rank correlation coefficient was calculated to ensure the pairing was effective $\left(\mathrm{r}_{\mathrm{s}}=0.8229, p<0.0001\right)$. The pollen types recorded could be split into two clear groups according to annual abundance, maximum daily concentration and the number of days in which levels exceeded 50 grains $\mathrm{m}^{-3}$ air (Table 1). Six taxa; ash,

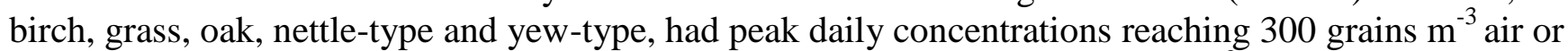
higher. In contrast the remaining taxa never reached daily peaks of 200 grains $\mathrm{m}^{-3}$ air. In terms of annual abundance the high group cumulated between 1850 and 6472 grains $\mathrm{m}^{-3}$ air, dependant on city and taxa analysed, compared to values of 0 to 796 grains $\mathrm{m}^{-3}$ air for the less abundant group. The abundant group were recorded at high levels ( $>50$ grains $\mathrm{m}^{-3}$ air) on multiple days at both cities unlike the remaining taxa. Of the six abundant pollen types, five were moderate to highly allergenic, the exception being nettle-type which is not generally thought to be allergenic. It should be noted, however, that nettle-type includes pollen from the plant pellitory-of-the wall (Parietaria judaica), which grows in the UK and is highly allergenic (Jäger 2004). The six taxa combined represent 90 and $88 \%$ of the total pollen count for Derby and Leicester respectively. Only the six taxa in the more abundant pollen group were subjected to further analyses.

Total annual abundance for birch, nettle-type, oak and ash were comparable between Derby and Leicester (Table 1). Grass was more abundant in Derby than Leicester, whilst yew-type was higher in Leicester than Derby. Maximum daily concentration for all six abundant taxa was very high ( $>150$ grains $\mathrm{m}^{-3}$ air $)$ at both cities. Absolute values were comparable for grass, birch and nettle whilst maximum daily concentration for yew-type was higher in Leicester than Derby; and conversely for oak and ash, higher in Derby than Leicester. The number of days with high counts was comparable for grass, birch, oak and ash, however, there were more high days in Leicester than Derby for nettle-type and yew-type, high being defined as greater than 50 grains $\mathrm{m}^{-3}$ air.

Over $99.5 \%$ of the total birch, grass, nettle and oak pollen recorded during the twelve months was from the 2006 calendar year (Table 2) enabling start and finish dates to be calculated using the $95 \%$ criterion (Andersen 1991). In Leicester 3.53\% of the total ash recorded was from 2007, so the end of the season was defined by the Derby dates alone. Yew-type pollen was recorded in high quantities in both years so no start and finish dates were calculated. To enable other comparisons, the end of the 2006 season, and the start of the 2007 season were defined as per Fehér \& Járai-Komlódi (1997) and the two partial seasons used together as they covered a full twelve month period. Birch and grass pollen season start and finish dates were very similar at both sites, whilst nettle exhibited a slightly longer season end tail in Derby. The oak season in Derby was prolonged in both directions.

There were highly significant positive correlations between the counts obtained for each taxa from the two sites (Table 3) and also between temperature and rainfall measurements at the two cities for the same time period. The correlations between temperature variables were much stronger than that for rainfall.

Line charts showing the average number of pollen grains $\mathrm{m}^{-3}$ air day ${ }^{-1}$ show highly similar trends, although absolute peak values vary with some taxa (Fig. 1). Bland-Altman plots (Fig. 2) show little discrepancy between the amounts of pollen counted by the two sites on any given day, although birch, grass, and nettletype show tighter agreements than ash, oak and yew-type as indicated by less distance between the upper 
and lower confidence levels (represented by the dotted lines). Pearson product moment correlation of the difference versus average data generated in the Bland-Altman analyses showed no significant trend in the differences between the counts from the two sites as the average count increased for grass, nettle-type, oak and yew-type pollen (Table 4). The two pollen types with the shortest seasons (ash and birch, with 21 and 20 days respectively) showed weak trends, with ash exhibiting a significant but weak positive trend and birch exhibiting a significant but weak negative trend ( $p=0.019$ and 0.0204 respectively).

For both cities, each day during the grass pollen season was classified as having low, moderate, high or very high levels of grass pollen according to the UK accepted threshold levels (Smith and Emberlin 2005). In addition a further seven days at the beginning and end of the season were analysed to capture the tails. As seen in Table 5, the majority ( $71 \%$ ) of the days were classified identically in both cities. The remaining days, with a single exception, varied by only a single category e.g. low or moderate, moderate or high, high or very high. Weighted kappa statistics comparing the grass pollen levels from both cities (Table 6) showed almost perfect agreement $(\mathrm{k}=0.871)$ between the values for each city.

As there are no accepted threshold guidelines for the other pollen taxa analysed, the grass forecasting levels were used to classify each day during the respective seasons (extended by 7 days each way) for the remaining five taxa. As with the grass levels, weighted kappa analysis showed substantial or almost perfect agreement between the two data sets for all the pollen types analysed (Table 6).

In 2007 and 2008 for the grass and nettle pollen seasons, there was a highly significant positive correlation between the counts recorded from both cities (Table 7). Line charts showing the average number of pollen grains $\mathrm{m}^{-3}$ air day ${ }^{-1}$ show near identical trends; and the Bland-Altman plots show little discrepancy between the amounts of pollen counted by the two sites on any given day (Fig. 3). Pearson product moment correlation of the difference versus average data generated in the Bland-Altman analyses (Table 7) showed no significant trend in the differences between the counts from the two sites for grass and nettle in 2007, and nettle in 2008. Grass counts during 2008 showed a weak but statistically significant negative trend. Weighted kappa analysis showed substantial or almost perfect inter-site agreement between the two cities grass and nettle seasons (extended by 7 days in one direction) when the days were classified as low, moderate, high or very high (Table 7).

\section{Discussion}

\subsection{Defining the Pollen season}

At least ten different criteria for calculating the length of pollen seasons have been published (Jato et al. 2006). The two most popular methods involve either defining the start of the season as the date in which the cumulative count reaches a pre-defined quantity, eg. Sum75, (Driessen et al. 1990; Emberlin et al. 1999), a technique often used for forecasting purposes during the season with no defined end point, or defining the season retrospectively as the period during which a defined percentage of the annual total was counted with the remaining percentage equally divided either side of the season e.g. 90\% (Andersen 1991; Piotrowska 2004), 95\% (Andersen 1991; Rodriguez-Rajo et al. 2004; Mendez et al. 2005) and 98\% (Galán et al. 1995). The retrospective percentage technique eliminates the long tails of low values at the start and end of the seasons which could otherwise introduce bias to the results during statistical analysis (Galán et al. 1995). The $98 \%$ criterion was shown to yield the longest grass season in a multi-year, multi-city study and resulted in a long tail at the end of the season (Jato et al. 2006). When applied to the data in this study, the $90 \%$ criterion shortened the season to an extent that excluded the first high $\left(>50\right.$ grains $\mathrm{m}^{-3}$ air day $\left.{ }^{-1}\right)$ grass day of the year (data not shown). For these reasons the $95 \%$ criterion was used to define the season for both cities, and where discrepancies in the start and finish date occurred, the longest period that encompassed $95 \%$ for both cities was used for further analyses.

It was not possible to use the $95 \%$ criterion to define the ash and yew-type pollen seasons. As detailed in the results section, only Derby dates were used to calculate the ash season using the $95 \%$ criterion. No season dates were attributed to yew-type pollen, but for the purposes of comparing data the method of Fehér and Járai-Komlódi (1997) was used to define the end of the 2006 and start of 2007 yew-type pollen seasons. The 
2007 start date being defined as the day when a concentration of 3 grains $\mathrm{m}^{-3}$ air was consistently exceeded, i.e. the pollen concentration was above 3 grains $\mathrm{m}^{-3}$ air on at least 5 days during the following week. The 2006 end-date being defined inversely as the last day on which the concentration was consistently still over 3 grains $\mathrm{m}^{-3}$ air.

The 2007 and 2008 grass and nettle seasons were defined using the 95\% criterion based on the Leicester data only. Leicester winter months 2007/08 and 2008/09 were not counted, however the 2006 data showed that less than $0.3 \%$ of the annual grass and nettle counts are produced within this period, and therefore these missing data would have minimal if any impact on the season dates. In addition, historical data from Derby provides further support that the winter months contribute very little towards the grass and nettle seasons. Derby pollen was recorded consistently between 1991 and 2005. During the periods $1^{\text {st }}$ Jan to $4^{\text {th }}$ Feb and $1^{\text {st }}$ Oct to $31^{\text {st }}$ Dec, the total grass count contributed to between 0.3 and $0.7 \%$ of the annual total $($ mean $=0.45)$, and for nettle 0.2 to $1.7 \%$ (mean $=0.62$ ) (data unpublished).

\subsection{Pollen abundance}

One of the key aims of this study was to determine whether a forecast based on data from one site would be sufficient for both cities. Pollen forecasts have many functions, many of which are related to hayfever. These include being used to diagnose the causative agent of an individual's hayfever, to warn sufferers on the start and severity of a particular season (Peternel et al. 2004), and also to assist with the timing for hayfever related clinical trials (Davies and Smith 1973). For specific pollen to be a serious risk of causing hayfever it needs to be both allergenic and present in quantities that can elicit a response, therefore only the more abundant pollen types were subjected to further analysis in the study. Days with high counts were defined as those when the maximum daily concentration was higher than 50 grains $\mathrm{m}^{-3}$ air. This is the threshold used in the UK to define high grass pollen days, based on the observation by W. Frankland and R. Davies that when the mean daily concentration of grass pollen grains in the air of central London exceeded 50 grains $\mathrm{m}^{-3}$, all of their patients in the area who were clinically sensitive to grass pollen experienced symptoms (Davies and Smith 1973). Whilst it is acknowledged that not all pollen types will cause symptoms at the same threshold values, there are no other threshold values for the other pollen types based on UK clinical data. The group of pollen types defined as abundant were present at high levels for between eight and thirty-three days over the study period and therefore represent the key taxa used for the pollen forecasting service. In contrast the remaining pollen types that made up the less abundant group never reached high levels at both cities. In fact only three pollen types reached high levels at either site, pine-type on one day in Derby, and plantain and plane for three days and two days respectively in Leicester. Plantain and pine-type are considered to have low allergenicity and plane moderate to high. The six taxa in the abundant group in this study are consistent with the most abundant pollen types in a 21 year study in Switzerland, and four of them are in the list of the most important aeroallergens in Europe (Clot 2003). The Swiss study also listed pine-type as being highly abundant, which in this study was the seventh most abundant at both sites, but clearly less abundant than the other six.

\subsection{Pollen season characteristics}

There are a number of different characteristics that can be used to describe the pollen season. Those used in this study include annual abundance, maximum daily concentration, number of days with high counts, season start date and season end date. There was no consistent difference noted between the two cities, and the differences that were observed were both pollen and method of observation specific. For example, oak showed consistency between the two cities in terms of annual abundance, maximum daily count and number of high days and yet clearly exhibited a prolonged season in both directions in Derby compared to Leicester. Grass was consistent between both cities in terms of maximum daily count, number of high days, and start and end of season, however, the annual abundance was clearly higher in Derby. Yew-type was more abundant and reached a higher maximum daily count in Derby than Leicester, but was at high levels for two days longer in Leicester than Derby. This highlights the fact that caution must be exercised when comparing two sites based on these types of characteristics, and warns against the use of a single measurement such as start date for comparing seasons. 
4.4 Comparison between the Leicester and Derby pollen seasons

Regardless of how the counts from the two cities were compared, there was clearly a very strong relationship between the data. For all six taxa analysed, the counts from the two cities were correlated in a strong, highly significant and positive manner, as were minimum and maximum temperature. Rainfall was also highly significantly correlated between the two sites, however the relationship was not as strongly positive. The implication from this is that rainfall can vary between the two sites, and this may have an effect on the pollen levels recorded, whereas temperature is fairly stable and therefore less likely to be a factor in any differences in the pollen counts.

Pollen concentration trends between the two sites were similar for all six taxa; however, the absolute peak values did vary. To see if differences in peak values had an effect on the corresponding forecast, each day was categorised for each taxa as having low, moderate, high or very high pollen levels. The numbers of days with agreeing classifications compared to non agreement was compared using weighted kappa statistics.

Kappa statistics is a means of comparing inter-observer variation, or in the case of this study, inter-site variation. Weighting the kappa statistic takes into consideration how far apart any discrepancies are. A difference of a single category, such as high to very high, would be considered in higher agreement than one of two categories, such as moderate to very high. A kappa statistic of 0.81 to 0.99 is considered to be almost perfect agreement, and that of 0.61 to 0.80 substantial agreement (Viera and Garrett 2005). Birch, grass, nettle-type and oak showed almost perfect agreement, and ash and yew-type substantial agreement.

A difference of a single pollen grain can lead to a day being classified into a different category e.g. 29 grains is classified as low, 30 grains moderate. These discrepancies will affect any comparisons based on classifications, such as the kappa statistic. An alternative means of assessing inter-observer variation is the Bland-Altman plot (Bland and Altman 1999), which compares the actual counts and plots the data graphically. In addition a Pearson product moment correlation is calculated to assess bias in the dataset. In general, the Bland-Altman plots showed little discrepancy between the amounts of pollen counted by the two sites on any given day, with four of the six taxa exhibiting no bias, and two taxa exhibiting weak trends.

\subsubsection{Comparing the abundant tree pollen taxa}

The ash tree (Fraxinus) belongs to the olive family, and for many years was considered as being important only as secondarily allergenic pollen due to cross-reactions with pollen from the olive tree (Olea), considered to be the most allergenic pollen in the Mediterranean. Since 1991, however, ash has been included in the list of the major allergenic pollen in Europe (Peeters 2000). A recent review of allergenic pollen has suggested that ash rarely induces allergic respiratory symptoms (D'Amato et al. 2007). At both Derby and Leicester sites, ash pollen was the sixth most abundant pollen type reaching high levels on ten or more days during the twelve month main study period. The trends were comparable and the season start dates identical. There was good correlation between the two sites, although this was the weakest of the six taxa analysed, possibly reflecting the smaller dataset due to it being the least abundant of the six and having one of the shortest seasons. The Bland-Altman showed good agreement, although there was a statistically significant weak positive trend in the dataset. This weak positive trend occurs when Derby has higher counts on high days, with Leicester typically having higher counts on lower count days, which is also seen when the data is displayed graphically. After classifying the days as low, moderate, high or very high, the agreement between the sites was substantial, implying it is possible to use one dataset to forecast for both sites for ash pollen.

Birch pollen (Betula) is considered to be one of the most allergenic aeroallergens, especially in Northern European countries (Adams-Groom et al. 2002; Corden et al. 2000; D'Amato et al. 2007). In terms of abundance during the main study period (April 06 to 07), birch pollen ranked $2^{\text {nd }}$ in Derby, and $3^{\text {rd }}$ in Leicester in terms of total abundance, and first for both cities in terms of max counts in any given day. Season start and finish dates were within one day of each other at both sites and the data was very highly correlated. The peaks and troughs in pollen counts were mirrored almost perfectly between the two sites. Bland-Altman showed a very tight relationship between the counts from both sites, although there was a weak but significant negative trend in the dataset. This trend suggests that Derby counts were higher than 
Leicester when the counts were lower; and lower than Leicester when the counts were higher; however, closer inspection of the data suggests this may be an artefact rather than a true statement. Kappa analysis after classifying the days as having low, moderate, high or very high birch pollen counts shows the two sites to be in almost perfect agreement. These results indicate that data from either site can be used to forecast for both.

There are two main oak tree species found throughout the East Midlands, UK Quercus robur (English oak) and Quercus petraea (Sessile oak). Whilst oak is considered to be only a moderate allergen (Jäger 2004; Egger et al. 2008), there is evidence that it is has had clinical significance in the study area (Ross et al. 1996). Oak was the fifth most abundant pollen type for both cities during the main study period (April 06 to 07). With a total abundance of over 2,000 grains at both sites, this was a relatively high year for oak pollen. A study in Derby from 1970 to 1997 recorded only one year with levels that was higher than this (Corden and Millington 1999). Oak appeared to exhibit a prolonged season in Derby compared to Leicester, starting three days earlier, and ending thirteen days later; however, the actual trends are very similar with the main peaks coinciding perfectly. The counts for the two sites were highly correlated; the Bland-Altman plot showed good agreement with no bias within the dataset, and the kappa analysis after each day had been described as having low, moderate, high or very high counts showed almost perfect agreement. This would suggest that forecasting for both sites can be based on data from a single site, and cautions against the use of season start and finish dates as sole indicators for agreement between multiple sites.

Due to an inability to distinguish between them morphologically, pollen from Taxaceae (yew family) and Cupressaceae (cypress, a conifer family) are grouped together as yew-type. The cypress family is known for moderate to high allergenicity (Jäger 2004), whereas yew pollen is considered to be low. The grouping of Taxaceae and Cupressaceae in one type has artificially augmented the importance of this group (Clot 2003). The diversity of trees and shrubs that make up this group could potentially also explain the high number of pollen peaks found over three consecutive months (Feb to April). Even with the diversity of plants that make up this group and the fact that many trees from this group are planted as ornamentals, all the peaks and troughs are in alignment between the two sites, albeit with Derby peaks being higher than Leicester in April, and Leicester being higher than Derby in February and March. There is a very high correlation between the data from both sites, the Bland-Altman plot shows good correlation, with no significant trend in the data and the kappa analysis after allocating the days to low, moderate, high and very high showed substantial agreement. For yew-type pollen it can be concluded that data from one site would be sufficient to forecast pollen levels from both.

\subsubsection{Comparing nettle and grass pollen over three consecutive seasons}

The Urticaceae family consists of more than 50 genera, of which the two most important are Urtica (nettle) and Parietaria (pellitory of the wall). Both Urtica and Parietaria are common weed plants, with Urtica being more ruderal than Parietaria (Vega-Maray et al. 2003). Parietaria pollen grains elicit severe pollinosis, however, it is not possible to readily distinguish Parietaria grains from Urtica by pollen morphology so in this study the two pollens are grouped together under the term nettle-type. Both are found in the area around the two study sites analysed in this study, although the exact distribution of them is not known. Nettle-type is clearly a key component of the aero flora for both cities, being the second highest pollen type in terms of abundance in Leicester and third in Derby during the main study period (April 0607). In the two subsequent years, even with the reduced counting period, the total abundance of nettle-type in both cities was even higher than in 06-07 (data not shown). In general a single species will exhibit a typical pollen distribution, with a lag at the start and end and a clear peak nearer to the start of the season than the end. Nettle-type pollen does not follow this pattern, in part due to the different flowering times of the different species that make up the group. For example, Urtica dioica flowers from June to August, Urtica urens from June to September, and Parietaria judaica from June until October (Corden and Millington 1991). All three species named can be found in the study area. Whilst there may be differences in the exact species composition between Leicester and Derby, which may explain the few discrepancies noted in peaks and troughs towards the end of the 2007 season, in all three years there was a high correlation between the counts for both cities, and substantial agreement between the counts as indicated by both kappa 
statistics and the Bland-Altman plot. In addition no bias was found in the dataset after Bland-Altman analyses had been implemented in any year. Taken together it can be argued that counts from either site would be sufficient to forecast the nettle-pollen levels for both cities.

The grass family Poaceae (Gramineae) is very large and consists of over 600 genera, including grasses of lowlands and meadows, as well as cereal crops such as oats, barley and wheat. Grass pollen is the primary cause of pollinosis in many parts of the world, including the UK (Emberlin 1997, D'Amato et al. 2007). In the East Midlands, UK during the study period April 06 to April 07, grass ranked first in terms of total abundance in Derby, and fourth in Leicester. Maximum daily counts for both cities were almost identical, and both cities had nearly 30 days with greater than 50 grains $\mathrm{m}^{-3}$ air day ${ }^{-1}$. This is the threshold at which all of patients in the area clinically sensitive to grass pollen are likely to experience symptoms (Davies and Smith 1973). Season start dates were within two days of each other, and end dates identical. There was a very high correlation between the counts; and whilst absolute pollen counts varied, peaks and troughs mirrored each other almost perfectly. The Bland-Altman plot showed a tight relationship between the counts from both sites, with no bias in the dataset. Most of the days during the pollen season were at comparable levels according to classification groups, with only one day out of the 70 days analysed being more than one classification out. Kappa analysis of this data showed almost perfect agreement between the classifications at both sites. 2006 data clearly shows that grass pollen from one site can generate a forecast applicable for both sites. In addition, as with nettle pollen, grass pollen was recorded for a further two years; 2007 and 2008. As with 2006, the Bland-Altman plot shows a very tight agreement between counts from both cities, and peaks and troughs mirror each other almost perfectly. Whilst no bias was found in 2006 or 2007, a weak but significant negative trend was found in the 2008 dataset, suggesting that Derby counts were higher than Leicester when the counts were lower; and lower than Leicester when the counts were higher, but a closer inspection of peaks and troughs showed that this was not the case. There was a very high correlation between counts; and kappa analysis of data after classifying each day as having low, moderate, high or very high counts, showed almost perfect agreement. Data from 2007 and 2008 therefore support the assertion that a forecast based on grass data from one of the sites will be accurate enough to represent both.

\subsection{General discussion}

Most comparative between site pollen studies from Europe have assessed regions that are geographically divergent. For example, between different European countries (Alcázar et al. 2009; Corden et al. 2002; Jäger et al. 1996; Piotrowska 2004; Spieksma et al. 2003), or between cities in different regions of the UK (Adams-Groom et al. 2002; Morrow Brown and Jackson 1978b). This study was unique in that it analysed two sites that represent two different cities from a specific geographical region (East Midlands, UK) that were relatively close together; $41 \mathrm{~km}$ (about 25 miles). Over three consecutive seasons, both grass and nettle-type pollen levels were shown to be consistent between the two cities. Methods of analysis comparing the absolute data (Bland-Altman) and those that compared classifications of the data (kappa statistics after classifying the days as low, moderate, high and very high) showed tight agreement and substantial or almost perfect agreement respectively. This study has shown that, for the purpose of pollen forecasting, the count from one site in the region is suitable for forecasting for the whole region. This finding was supported by the abundant tree pollen data collected during the first year of the study. Together the abundant tree taxa, grass and nettle-type pollen represented over $88 \%$ of the air spora in the East Midlands, UK.

A similar study in Sydney Australia counted pollen from three sites in a 30km region, and concluded that, whilst for clinical trial purposes data collection must be local and applicable to the study population, for informing the public about pollen counts, the count from 1 trap is a reasonable estimation in a $30 \mathrm{~km}$ region (Katelaris et al. 2004).

\section{Conclusion}

Pollen counts were clearly highly correlated between the two sites analysed. Grass is the most allergenic pollen in the region, and for three consecutive years this study has shown that both grass and nettle-type pollen data from one site is suitable for forecasting for the region. This was supported in the first year of the study by the abundant tree pollen taxa; ash, birch, oak, and yew-type, not sampled in subsequent years. With 
the caveat that this would not apply in a region with restrictions to air flow such as a mountain range, or with extreme fluctuations in conditions as one would get from a coastline site, this study suggests that a forecast based on data from a single site may be suitable for forecasting in a $40 \mathrm{~km}$ region.

\section{Acknowledgments}

The authors are grateful to the Midlands Asthma and Allergy Research Association (MAARA) for providing funding to carry out this study; to Mike Greenwood, Elizabeth Taylor, and the rest of the team from the Faculty of Education Health and Sciences at the University of Derby for kindly changing the pollen traps; and to David Vince and Claire Barbour for providing weather data for Derby and Leicester respectively.

\section{References}

Adams-Groom, B., Emberlin, J., Corden, J., Millington, W. and Mullins, J. (2002). Predicting the start of the birch pollen season at London, Derby and Cardiff, United Kingdom, using a multiple regression model, based on data from 1987 to 1997. Aerobiologia 18:117-123.

Alcázar, P., Stach, A., Nowak, M. and Galán, C. (2009). Comparison of airborne herb pollen types in Córdoba (Southwestern Spain) and Poznan (Western Poland). Aerobiologia 25:55-63

Andersen, T. B. (1991). A model to predict the beginning of the pollen season. Grana 30:269-275.

BAF (1995). Airborne pollens and spores: a guide to trapping and counting. The British Aerobiology Federation.

Bland, J. M. and Altman, D. G. (1999). Measuring agreement in method comparison studies. Stat. Methods Med. Res. 8:135-160.

Caiola, M. G., Mazzitelli, A., Capucci, E. and Travaglini, A. (2002). Monitoring pollinosis and airborne pollen in a Rome university. Aerobiologia 18:267-275.

Clot, B. (2003). Trends in airborne pollen: An overview of 21 years of data in Neuchatel (Switzerland). Aerobiologia 19:227-234.

Corden, J. and Millington, W. (1991). A study of Gramineae and Urticaceae in the Derby area. Aerobiologia 7:100-106.

Corden, J. and Millington, W. (1999). A study of Quercus pollen in the Derby area. Aerobiologia 15:29-37.

Corden, J., Millington, W., Bailey, J., Brookes, M., Caulton, E., Emberlin, J., Mullins, J., Simpson, C. and Wood, A. (2000). UK regional variations in Betula pollen (1993-1997). Aerobiologia 16:227-232.

Corden, J., Stach, A. and Millington, W. M. (2002). A comparison of Betula pollen seasons at two European sites; Derby, United Kingdom and Poznan, Poland (1995-1999). Aerobiologia 18:45-53.

D'Amato, G., Cecchi, L., Bonini, S., Nunes, C., Annesi-Maesano, I., Behrendt, H., Liccardi, G., Popov, T. and van Cauwenberge P. (2007). Allergenic pollen and pollen allergy in Europe. Allergy 62:976-990.

Davies, R. R. and Smith, L. P. (1973). Forecasting the start and severity of the hay fever season. Clinical Allergy 3:263-267.

Driessen, M. N. B. N., Vanherpen, R. M. A. and Smithuis, L. O. M. J. (1990). Prediction of the start of the grass pollen season for the southern part of the Netherlands. Grana 29:79-86.

Egger, C., Focke, M., Bircher, A.J., Scherer, K., Mothes-Luksch, N., Horak, F. and Valenta, R. (2008). The allergen profile of beech and oak pollen. Clinical and Experimental Allergy 38:1688-1696.

Emberlin, J. C. (1997). Grass, tree and weed pollens, in Allergy and Allergic Diseases, A. B. Kay, ed., Blackwell Science, 835-857.

Emberlin, J., Mullins, J., Corden, J., Jones, S., Millington, W., Brooke, M. and Savage, M. (1999). Regional variations in grass pollen seasons in the UK, long-term trends and forecast models. Clinical and Experimental Allergy 29:347-356.

Epton, M. J., Martin, I. R., Graham, P., Healy, P. E., Smith, H., Balasubramaniam, R., Harvey, I. C., Fountain, D. W., Hedley, J. and Town, G. I. (1997). Climate and aeroallergen levels in asthma: A 12 month prospective study. Thorax 52:528-534.

Eriksson, N. E. (1978). Allergy to pollen from different deciduous trees in Sweden. Allergy 33:299-309.

Fehér, Z. and Járai-Komlódi, M. (1997). An examination of the main characteristics of the pollen seasons in Budapest, Hungary (1991-1996). Grana 36:169-174.

Fountain, D. W. and Cornford, C. A. (1991). Aerobiology and allergenicity of Pinus radiata pollen in New Zealand. Grana 30:71-75. 
Galán, C., Emberlin, J., Dominguez, E., Bryant, R. H. and Villamandos, F. (1995). A comparative analysis of daily variations in the Gramineae pollen counts at Codoba, Spain and London, UK. Grana 34:189198.

Hyde, H. A. and Adams, K. F. (1958). An atlas of airborne pollen grains. Macmillan \& Co Ltd, London.

Jager, S., Nilsson, S., Berggren, B., Pessi, A. M., Helander, M. and Ramfjord, H. (1996). Trends of some airborne tree pollen in the Nordic countries and Austria, 1980-1993 - A comparison between Stockholm, Trondheim, Turku and Vienna. Grana 35:171-178.

Jäger, S. (2004). Europe Polleninfo.org .http://www.polleninfo.org. Accessed $29^{\text {th }}$ April 2009.

Jato, V., Rodríguez-Rajo, F. J., Alcázar, P., de Nuntiis, P., Galán, C. and Mandrioli, P. (2006). May the definition of pollen season influence aerobiological results? Aerobiologia 22:13-25.

Katelaris, C. H., Burke, T. V. and Byth, K. (2004). Spatial variability in the pollen count in Sydney, Australia: can one sampling site accurately reflect the pollen count for a region? Annals of Allergy Asthma \& Immunology 93:131-136.

Keskin, O., Alyamac, E., Tuncer, A., Dogan, C., Adalioglu, G. and Sekerel, B. E. (2006). Do the leukotriene receptor antagonists work in children with grass pollen-induced allergic rhinitis? Pediatric Allergy and Immunology 17:259-268.

Lacey, M. E. and West, J. S. (2006). The Air Spora; a manual for catching and identifying airborne biological particles. Springer, Dordrecht.

Mendez, J., Comtois, P. and Iglesias, I. (2005). Betula pollen: One of the most important aeroallergens in Ourense, Spain. Aerobiological studies from 1993 to 2000. Aerobiologia 21:115-123.

Mirone, C., Albert, F., Tosi, A., Mocchetti, F., Mosca, S., Giorgino, M., Pecora, S., Parmiani, S. and Ortolani, C. (2004). Efficacy and safety of subcutaneous immunotherapy with a biologically standardized extract of Ambrosia artemisiifolia pollen: a double-blind, placebo-controlled study. Clinical and Experimental Allergy 34:1408-1414.

Morrow Brown, H. and Jackson, F. A. (1978a). Aerobiological studies based in Derby I. A simplified automatie volumetric spore trap. Clinical Allergy 8:589-597.

Morrow Brown, H. and Jackson, F. A. (1978b). Aerobiological studies based in Derby III. A comparison of simultaneous pollen and spore counts from the east coast, Midlands and west coast of England and Wales. Clinical Allergy 8:611-619.

Pajno, G. B., Vita, D., Parmiani, S., Caminiti, L., La Grutta, S. and Barberio, G. (2003). Impact of sublingual immunotherapy on seasonal asthma and skin reactivity in children allergic to Parietaria pollen treated with inhaled fluticasone propionate. Clinical and Experimental Allergy 33:1641-1647.

Peeters, A. G. (2000). Frost periods and beginning of the ash (Fraxinus excelsior L.) pollen season in Basel (Switzerland). Aerobiologia 16:353-359.

Peternel, R., Srnec, L., Culig, J., Zaninovic, K., Mitic, B. and Vukusic, I. (2004). Atmospheric pollen season in Zagreb (Croatia) and its relationship with temperature and precipitation. Int. J. Biometeorol. 48:186191.

Piotrowska, K. (2004). Comparison of Alnus, Corylus and Betula pollen counts in Lublin (Poland) and Skien (Norway). Annals of Agricultural and Environmental Medicine 11:205-208.

Rodriguez-Rajo, F. J., Dopazo, A. and Jato, V. (2004). Environmental factors affecting the start of pollen season and concentrations of airborne Alnus pollen in two localities of Galicia (NW Spain). Annals of Agricultural and Environmental Medicine 11:35-44.

Ross, A. M., Corden, J. M. and Fleming, D. M. (1996). The role of oak pollen in hay fever consultations in general practice and the factors influencing patients' decisions to consult. British Journal of General Practice 46:451-455.

Smith, M. and Emberlin, J. (2005). Constructing a 7-day ahead forecast model for grass pollen at north London, United Kingdom. Clinical and Experimental Allergy 35:1400-1406.

Spieksma, F. T. M., Corden, J. M., Detandt, M., Millington, W. M., Nikkels, H., Nolard, N., Schoenmakers, C. H. H., Wachter, R., de Weger, L. A., Willems, R. and Emberlin, J. (2003). Quantitative trends in annual totals of five common airborne pollen types (Betula, Quercus, Poaceae, Urtica, and Artemisia), at five pollen-monitoring stations in western Europe. Aerobiologia 19:171-184.

Taylor, P.E., Jacobson, K.W., House, J.M. and Glovsky, M.M. (2007). Links between Pollen, Atopy and the Asthma Epidemic. International Archives of Allergy and Immunology 144:162-170 
Vega-Maray, A. M., Valencia-Barrera, R. M., Fernández-González, D. and Fraile, R. (2003). Urticaceae pollen concentration in the atmosphere of North Western Spain. Annals of Agricultural and Environmental Medicine 10:249-255.

Viera, A. J. and Garrett, J. M. (2005). Understanding interobserver agreement: the kappa statistic. Family Medicine 37:360-363. 
Table 1 Pollen types identified by morphological characteristics from Derby (DBY) and Leicester (LTR) and their respective allergenicity (A) where 0 is none or very low, 1 is low, 2 is low to moderate, 3 is moderate, 4 is moderate to high and 5 is high. Included are total annual abundance $(\mathrm{N})$ and maximum daily concentration (M) in grains $\mathrm{m}^{-3}$ air, and number of days with higher than 50 grains $\mathrm{m}^{-3}$ air $(\mathrm{T})$.

\begin{tabular}{|c|c|c|c|c|c|c|c|c|}
\hline \multirow[t]{2}{*}{ Common name } & \multirow[t]{2}{*}{ Latin name } & \multirow[t]{2}{*}{$\mathrm{A}^{*}$} & \multicolumn{2}{|c|}{$\mathrm{N}$} & \multicolumn{2}{|c|}{$\mathrm{M}$} & \multicolumn{2}{|c|}{$\mathrm{T}$} \\
\hline & & & DBY & LTR & DBY & LTR & DBY & LTR \\
\hline Grass & Poaceae & 5 & 6472 & 4982 & 435 & 442 & 29 & 28 \\
\hline Birch & Betula & 5 & 5724 & 5281 & 953 & 943 & 18 & 15 \\
\hline Nettle-type & Urtica, Parietaria judaica & 0,5 & 5692 & 5507 & 448 & 467 & 28 & 33 \\
\hline Yew-type & Taxaceae, Cupressaceae & 4 & 4693 & 6377 & 474 & 681 & 24 & 29 \\
\hline Oak & Quercus & 3 & 2643 & 2748 & 775 & 674 & 8 & 10 \\
\hline Ash & Fraxinus & 4 & 2108 & 1850 & 379 & 303 & 10 & 12 \\
\hline Pine-type & Pinaceae & $1^{2}$ & 796 & 499 & 81 & 38 & 1 & 0 \\
\hline Alder & Alnus & 4 & 507 & 485 & 37 & 32 & 0 & 0 \\
\hline Willow & Salix & 1 & 318 & 360 & 19 & 30 & 0 & 0 \\
\hline Elder & Sambucus & 2 & 225 & 160 & 26 & 16 & 0 & 0 \\
\hline Dock & Rumex & 4 & 160 & 33 & 21 & 3 & 0 & 0 \\
\hline Hazel & Corylus & 4 & 158 & 194 & 19 & 38 & 0 & 0 \\
\hline Elm & Ulmus & $1^{1}$ & 152 & 83 & 11 & 4 & 0 & 0 \\
\hline Sweet Chestnut & Castanea & 2 & 144 & 89 & 23 & 36 & 0 & 0 \\
\hline Rape-type & Brassica & 2 & 93 & 113 & 11 & 20 & 0 & 0 \\
\hline Plantain & Plantago & 1 & 89 & 472 & 4 & 139 & 0 & 3 \\
\hline Plane & Platanus & 4 & 81 & 401 & 11 & 159 & 0 & 2 \\
\hline Goosefoot & Chenopodiaceae & 2 & 77 & 103 & 6 & 8 & 0 & 0 \\
\hline Beech & Fagus & 2 & 72 & 22 & 15 & 5 & 0 & 0 \\
\hline Mugwort & Artemisia & 5 & 61 & 58 & 3 & 6 & 0 & 0 \\
\hline Poplar & Populus & $1^{1}$ & 37 & 91 & 6 & 18 & 0 & 0 \\
\hline Horse Chestnut & Aesculus & 2 & 32 & 51 & 4 & 8 & 0 & 0 \\
\hline Hornbeam & Carpinus & 2 & 25 & 259 & 3 & 40 & 0 & 0 \\
\hline Lime & Tilia & 0 & 24 & 72 & 2 & 12 & 0 & 0 \\
\hline Ragweed & Ambrosia & 5 & 0 & 0 & 0 & 0 & 0 & 0 \\
\hline
\end{tabular}

*Allergenicity information from Jäger (2004) except ${ }^{1}$ (Eriksson 1978) and ${ }^{2}$ (Fountain and Cornford 1991). 
Table 2 Season characteristics for the most abundant pollen types recorded in both cities. When dates are given, those for Leicester (LTR) are presented as the number of days before (-) or after (+) the respective Derby (DBY) date.

\begin{tabular}{lcccccccccccccccccc}
\hline & \multicolumn{2}{c}{ Ash } & \multicolumn{2}{c}{ Birch } & \multicolumn{2}{c}{ Grass } & \multicolumn{2}{c}{ Nettle } & \multicolumn{2}{c}{ Oak } \\
& DBY & LTR & DBY & LTR & DBY & LTR & DBY & LTR & DBY & LTR & DBY & LTR \\
\hline Total pollen grains m m $^{-3}$ air (all data) & 2108 & 1850 & 5724 & 5281 & 6472 & 4982 & 5692 & 5507 & 2643 & 2748 & 4693 & 6377 \\
Total pollen count (2006 only) & 2097 & 1785 & 5718 & 5274 & 6470 & 4979 & 5692 & 5507 & 2639 & 2742 & 2673 & 1788 \\
Contribution of 2007 data to total (\%) & 0.54 & 3.53 & 0.10 & 0.13 & 0.03 & 0.05 & 0.00 & 0.00 & 0.16 & 0.22 & 43.05 & 71.96 \\
Date season starts & $15 / 4 / 06$ & 0 & $22 / 4 / 06$ & +1 & $6 / 6 / 06$ & -2 & $7 / 6 / 06$ & -1 & $6 / 5 / 06$ & +3 & $\mathrm{n} / \mathrm{a}$ & $\mathrm{n} / \mathrm{a}$ \\
Date season ends & $5 / 5 / 06$ & $\mathrm{n} / \mathrm{a}$ & $11 / 5 / 06$ & 0 & $29 / 7 / 06$ & 0 & $10 / 9 / 06$ & -5 & $11 / 6 / 06$ & -13 & $\mathrm{n} / \mathrm{a}$ & $\mathrm{n} / \mathrm{a}$ \\
\hline
\end{tabular}


Table 3 Correlation between the pollen counts from Derby and Leicester for the abundant pollen taxa. In addition correlations between the temperature and rainfall for the two cities are given.

\begin{tabular}{cccc}
\hline Taxa & Spearman $\mathbf{r}$ & $\mathbf{9 5 \%}$ confidence interval & P value (two-tailed) \\
\hline Ash & 0.6710 & 0.3246 to 0.8587 & 0.0009 \\
Birch & 0.9504 & 0.8731 to 0.9811 & $<0.0001$ \\
Grass & 0.8778 & 0.7964 to 0.9279 & $<0.0001$ \\
Nettle & 0.8407 & 0.7660 to 0.8929 & $<0.0001$ \\
Oak & 0.7724 & 0.5915 to 0.8792 & $<0.0001$ \\
Yew-type & 0.8292 & 0.7515 to 0.8843 & $<0.0001$ \\
\hline Rainfall (mm) & 0.5364 & 0.4537 to 0.6100 & $<0.0001$ \\
Min temp & 0.9554 & 0.9448 to 0.9641 & $<0.0001$ \\
Max temp & 0.9792 & 0.9741 to 0.9832 & $<0.0001$ \\
\hline
\end{tabular}

Table 4 Pearson product moment correlation ( $r$ ) of the difference versus average data generated in the Bland-Altman analysis for each of the pollen data sets. Included is length of season $(\mathrm{n})$ in days.

\begin{tabular}{lccccc}
\hline Taxa & $\mathrm{n}$ & $\mathrm{r}$ & $\begin{array}{c}\text { 95\% confidence } \\
\text { interval }\end{array}$ & $\begin{array}{c}\text { P value (two- } \\
\text { tailed) }\end{array}$ & $\begin{array}{c}\text { significant correlation } \\
\text { (alpha=0.05) }\end{array}$ \\
\hline Ash & 21 & 0.5068 & 0.0960 to 0.7701 & 0.0190 & yes \\
Birch & 20 & -0.5141 & -0.7794 to -0.0926 & 0.0204 & yes \\
Grass & 56 & -0.1029 & -0.3562 to 0.1645 & 0.4506 & no \\
Nettle-type & 93 & -0.0543 & -0.2552 to 0.1511 & 0.6052 & no \\
Oak & 37 & -0.1413 & -0.4450 to 0.1915 & 0.4041 & no \\
Yew-type & 96 & 0.0914 & -0.1112 to 0.2867 & 0.3760 & no \\
\hline
\end{tabular}


Table 5 The number of days from each site with corresponding grass pollen counts according to classification levels. Data shown includes the full grass pollen season plus an additional 7 days at the start and end of the season to capture the tails.

\begin{tabular}{|c|c|c|c|c|c|}
\hline & \multicolumn{5}{|c|}{ Derby } \\
\hline & & $\begin{array}{l}\text { Low } \\
(0-29)\end{array}$ & $\begin{array}{c}\text { Moderate } \\
(30-49)\end{array}$ & $\begin{array}{c}\text { High } \\
(50-150)\end{array}$ & $\begin{array}{c}\text { Very high } \\
(>150)\end{array}$ \\
\hline \multirow[t]{4}{*}{ Leicester } & Low & 31 & 6 & & 1 \\
\hline & Moderate & 2 & 1 & 1 & \\
\hline & High & & 1 & 8 & 8 \\
\hline & Very high & & & 1 & 10 \\
\hline
\end{tabular}

Table 6 Weighted kappa statistics to demonstrate inter-site agreement after the days have been classified as having low, moderate, high or very high pollen counts, for all six pollen types. Analyses based on season data extended in each direction by an additional 7 days.

\begin{tabular}{lcc}
\hline Taxa & Quadratic weights & SE \\
\hline Ash & 0.755 & 0.167 \\
Birch & 0.916 & 0.167 \\
Grass & 0.871 & 0.118 \\
Nettle-type & 0.979 & 0.097 \\
Oak & 0.911 & 0.140 \\
Yew-type & 0.758 & 0.094 \\
\hline
\end{tabular}


Table 7 Correlation between the pollen counts from Derby and Leicester during the 2007 and 2008 grass and nettle seasons; Pearson product moment correlation ( $r$ ) of the difference versus average data generated in the Bland-Altman analysis, including length of season (n) in days; and weighted kappa statistics to demonstrate inter-site agreement for season data extended in one direction by an additional 7 days.

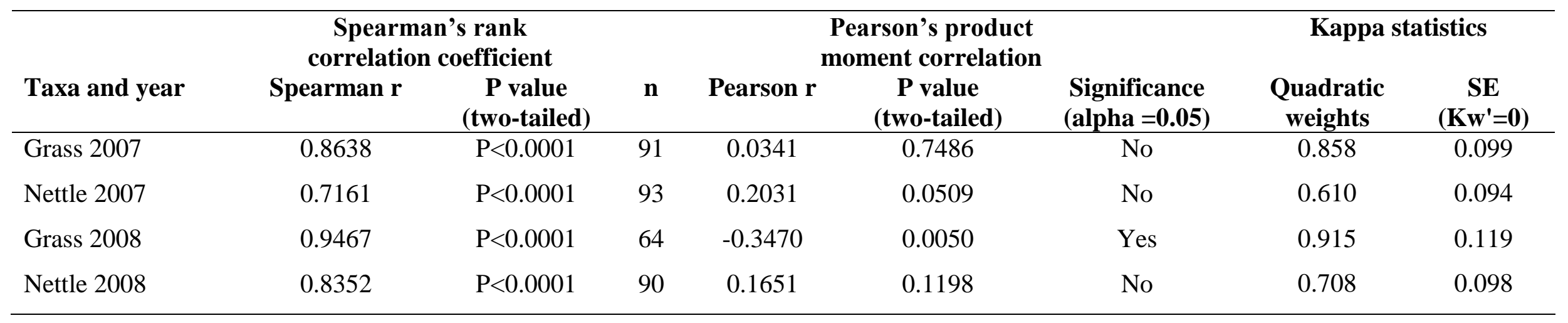


Fig. 1 Line graphs showing daily average pollen count during respective pollen season for both cities (a) ash (b) oak (c) birch (d) grass (e) nettle-type, and (f) yew-type.

Fig. 2 Bland-Altman plots showing difference against average pollen count each day for Derby and Leicester (a) ash (b) birch (c) grass (d) nettle-type (e) oak, and (f) yew-type. Dotted lines represent the 95\% confidence interval. Pollen counts were log transformed using $\ln (\mathrm{Y}+1)$ to normalise. The $\mathrm{x}$-axis is the mean pollen count on any given day, the $\mathrm{y}$-axis the difference between the mean and the actual value, with positive y values representing days when Derby counts are higher than Leicester and negative y values when Derby counts are lower.

Fig. 3 Left panel, Bland-Altman plots showing difference against average pollen count each day for Derby and Leicester. Dotted lines represent the 95\% confidence interval. Right panel, line graphs showing daily average pollen count during respective pollen season (a) grass 2007 (b) nettle 2007 (c) grass 2008, and (d) nettle 2008. 
a) 400

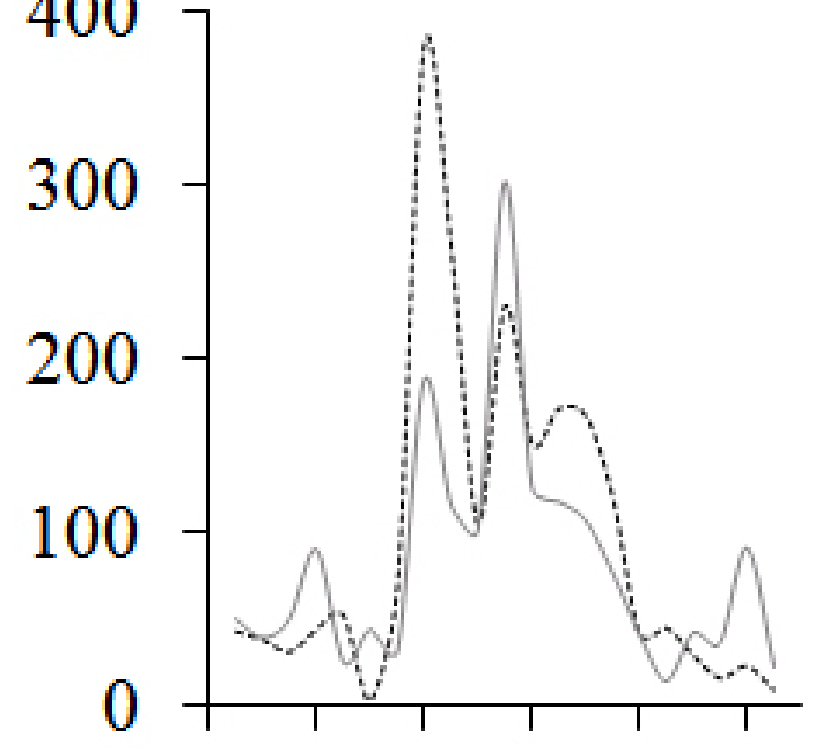

c) 1000

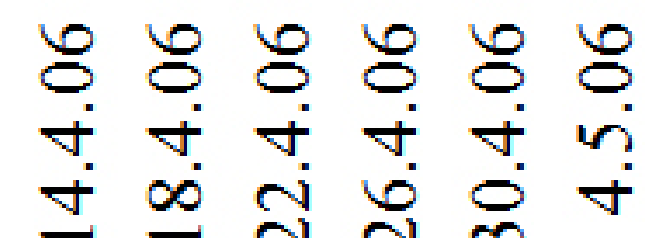

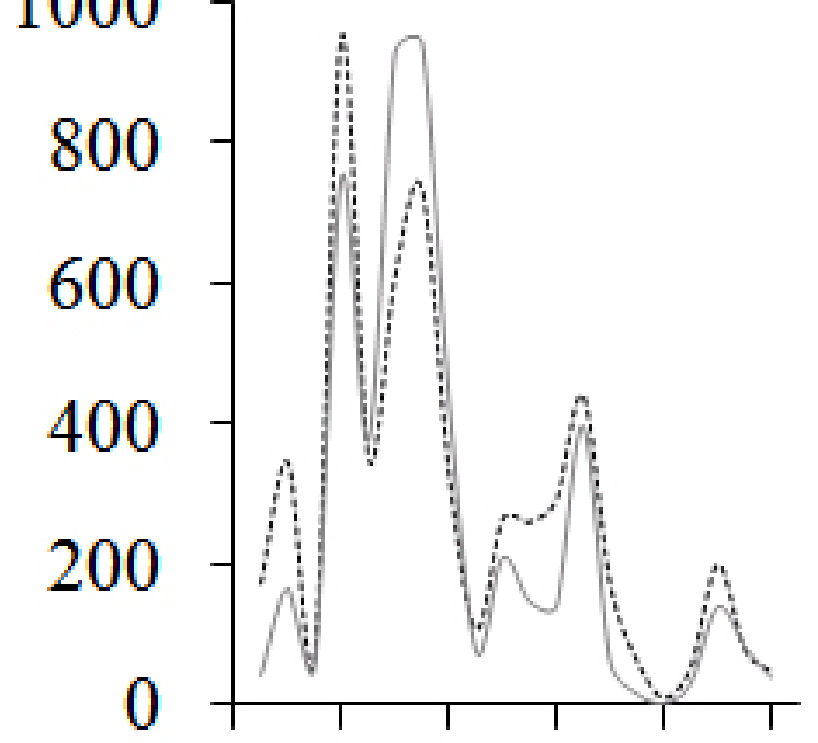

๖ ஃஃ

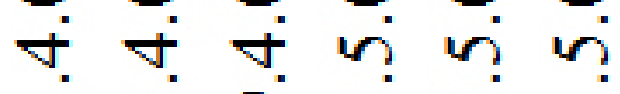
त ล จे

e) 500

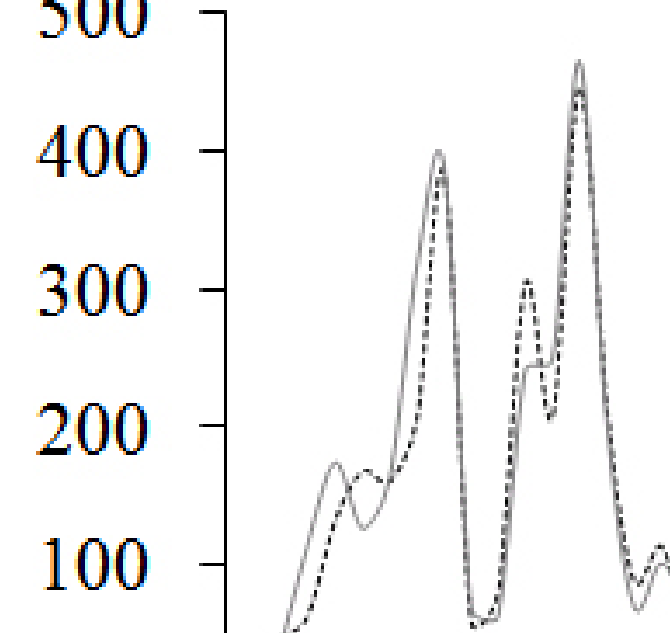

0

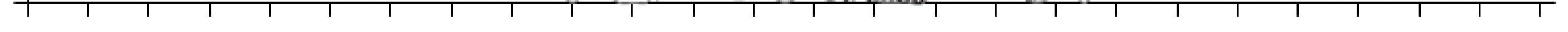

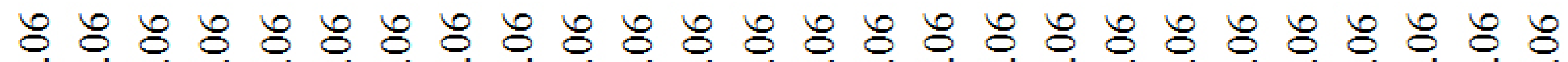
0 b 0 b

f

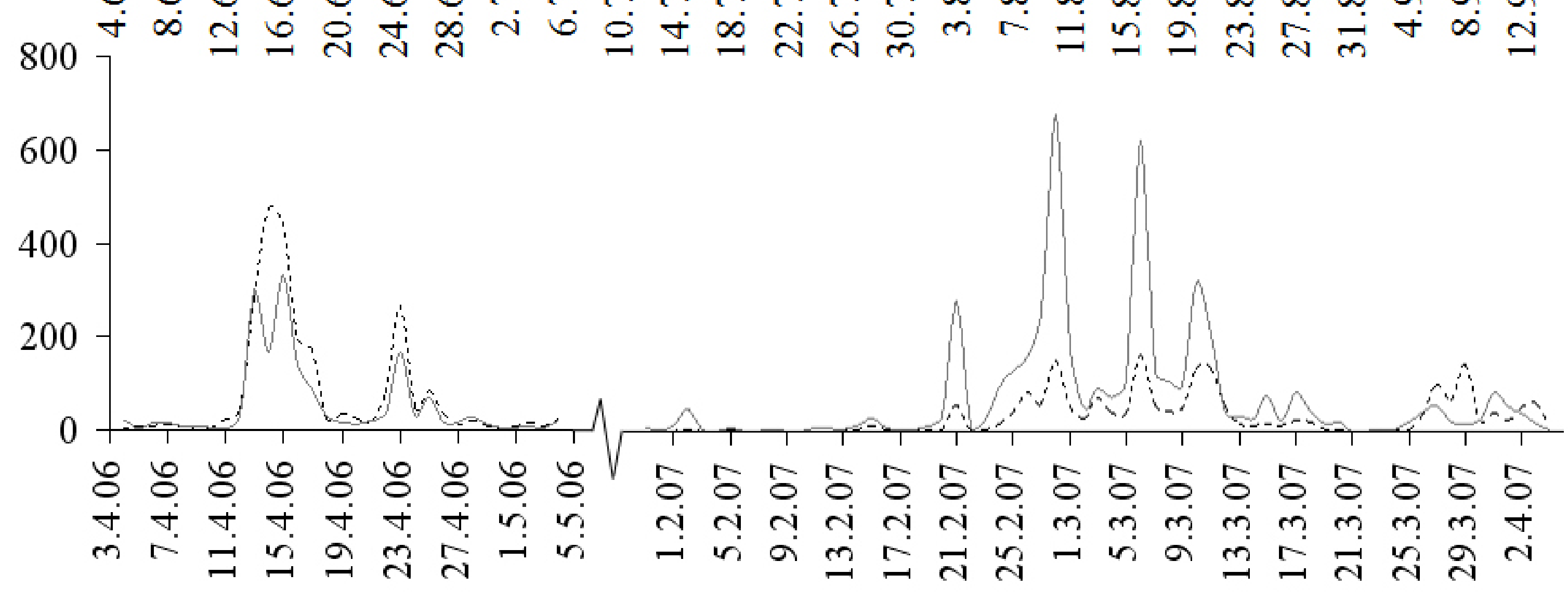


a)

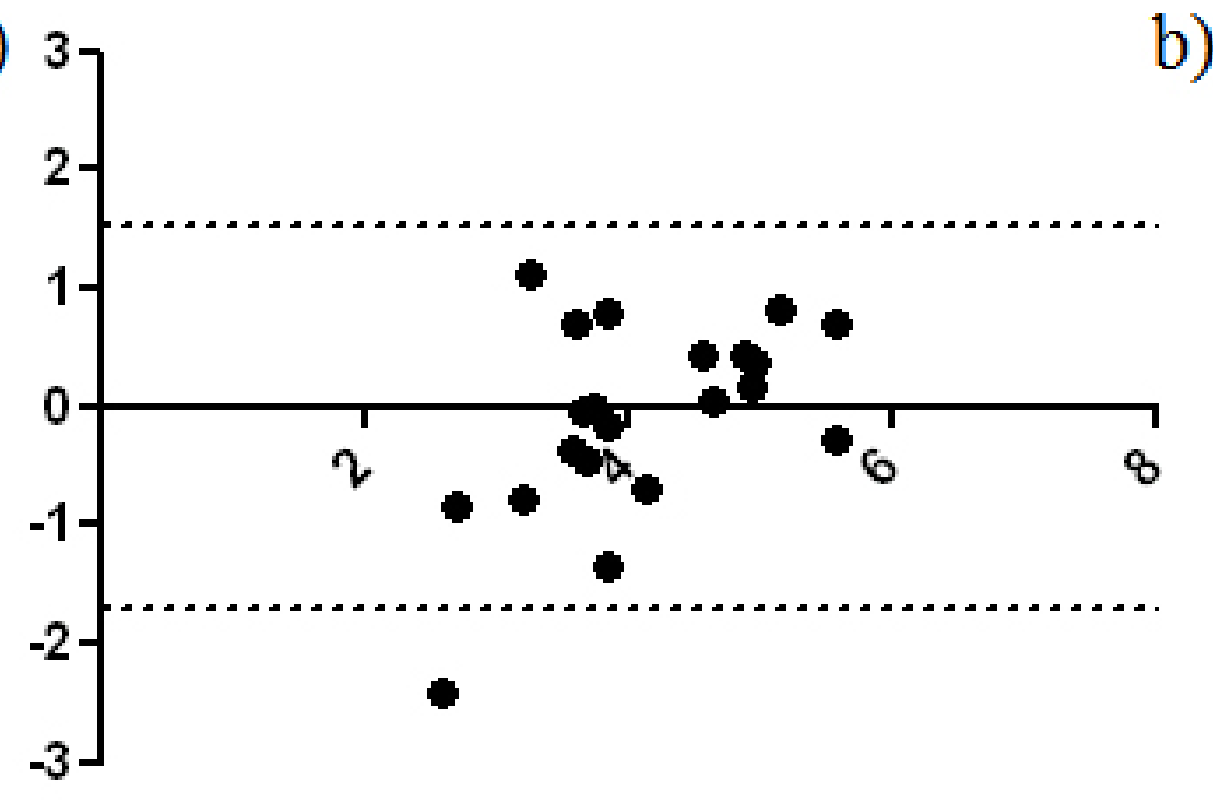

c)

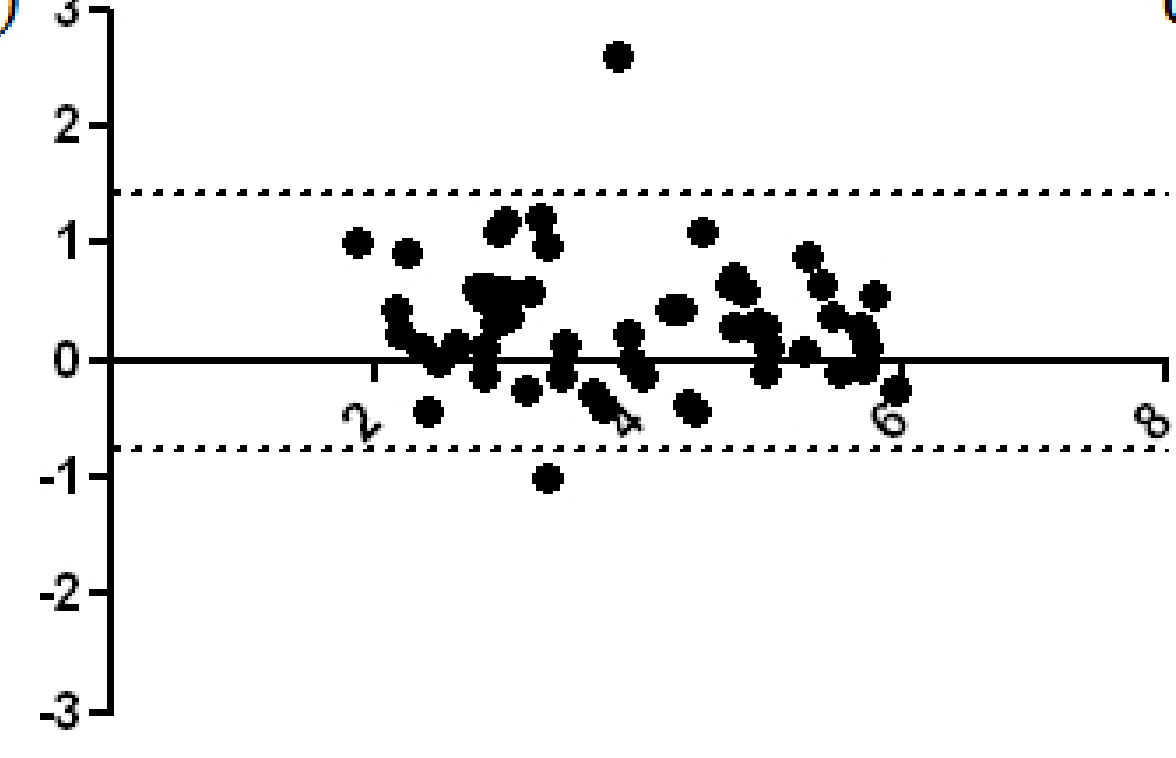

e)

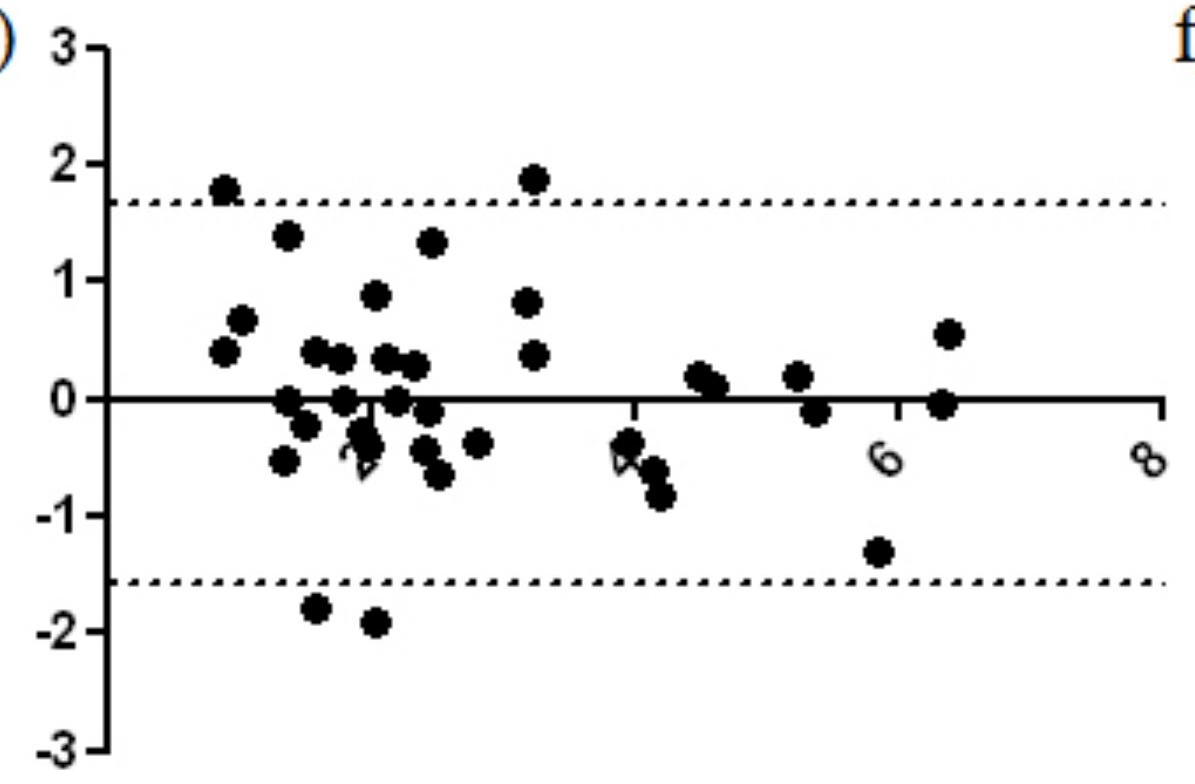

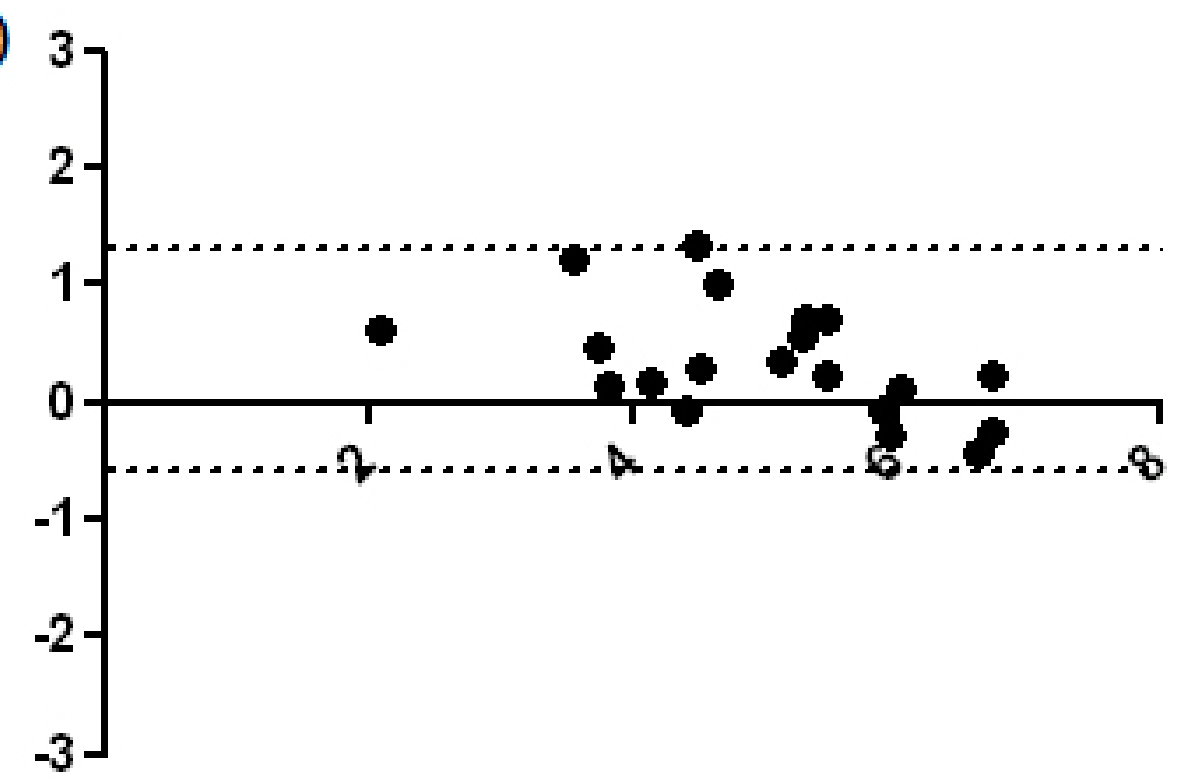

d)

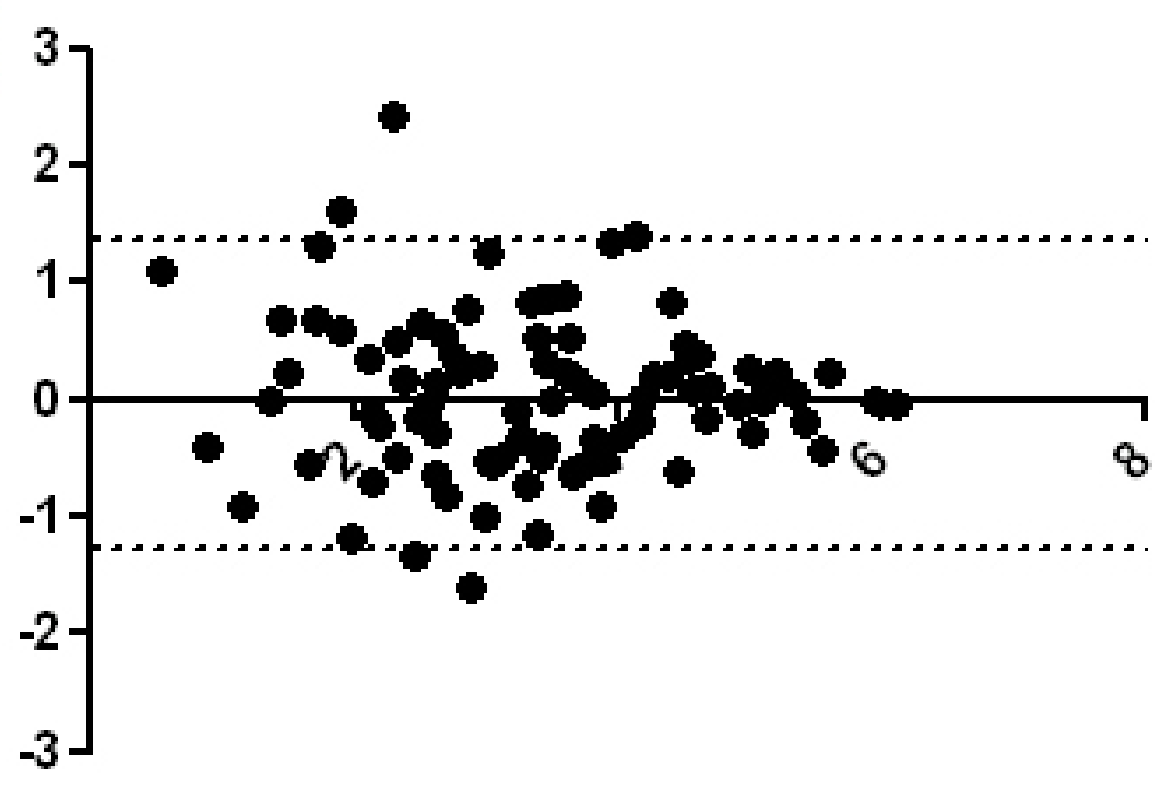

f)

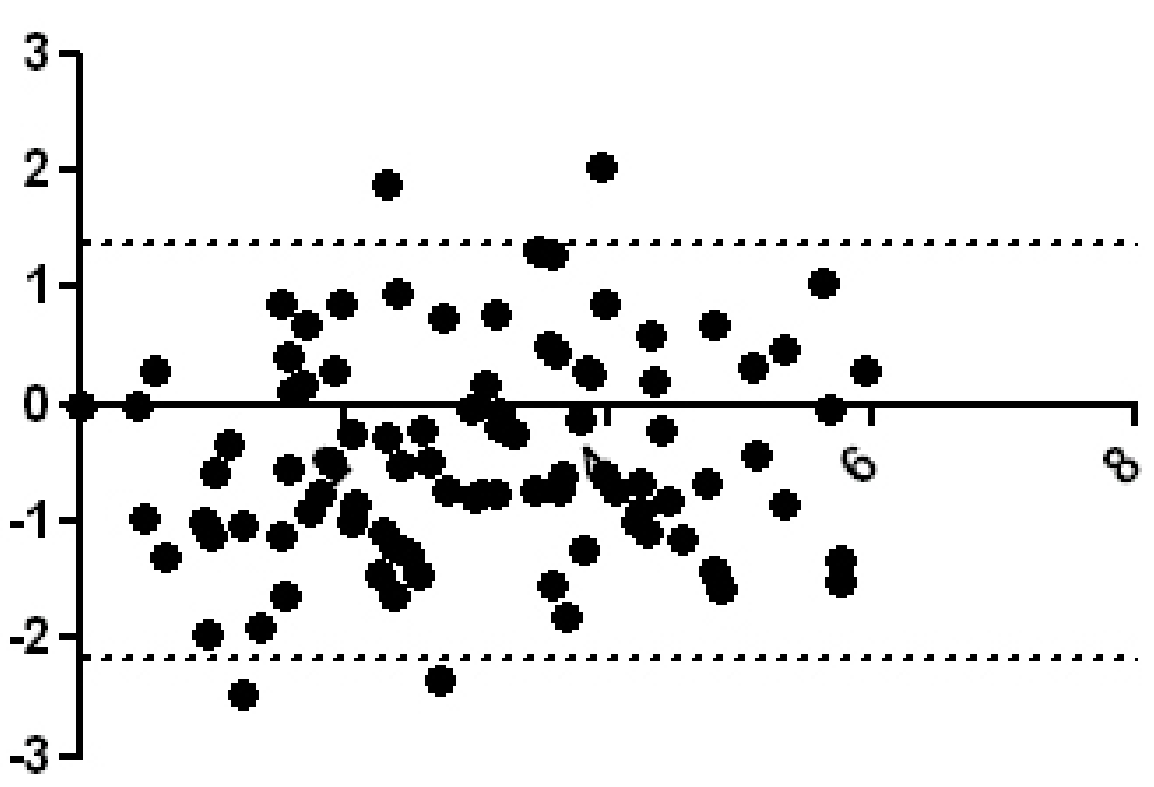


a) 3

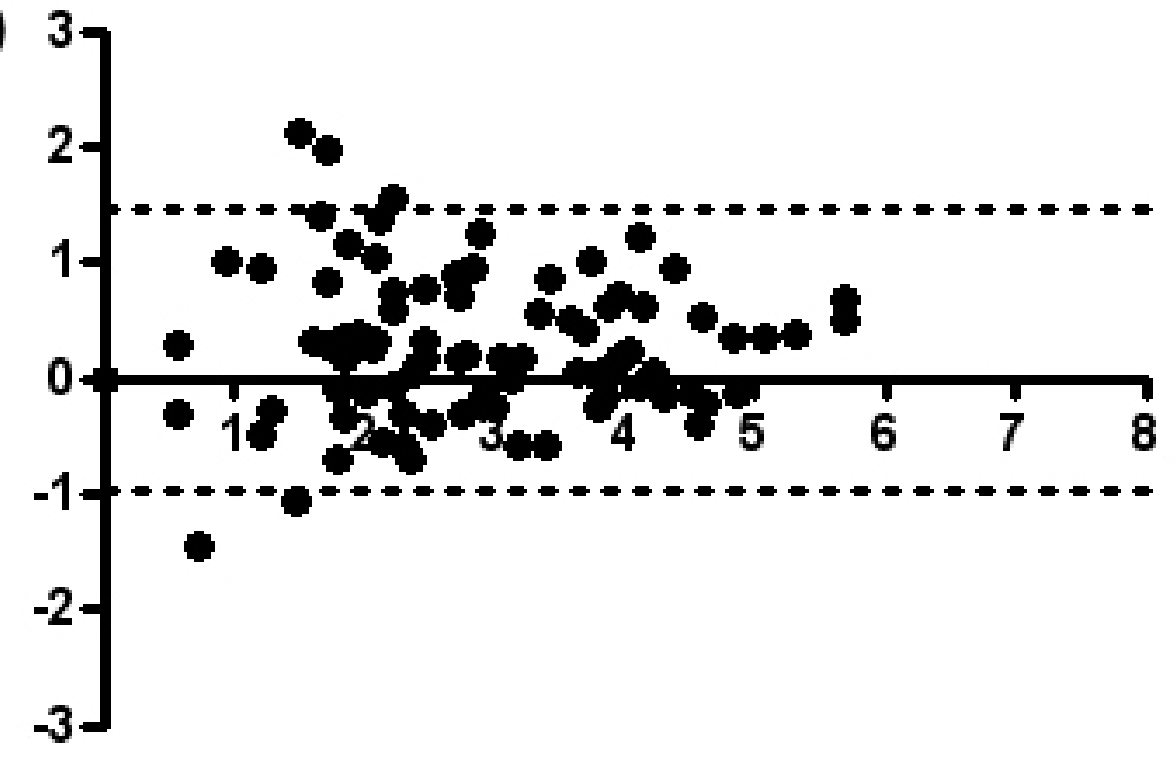

b)

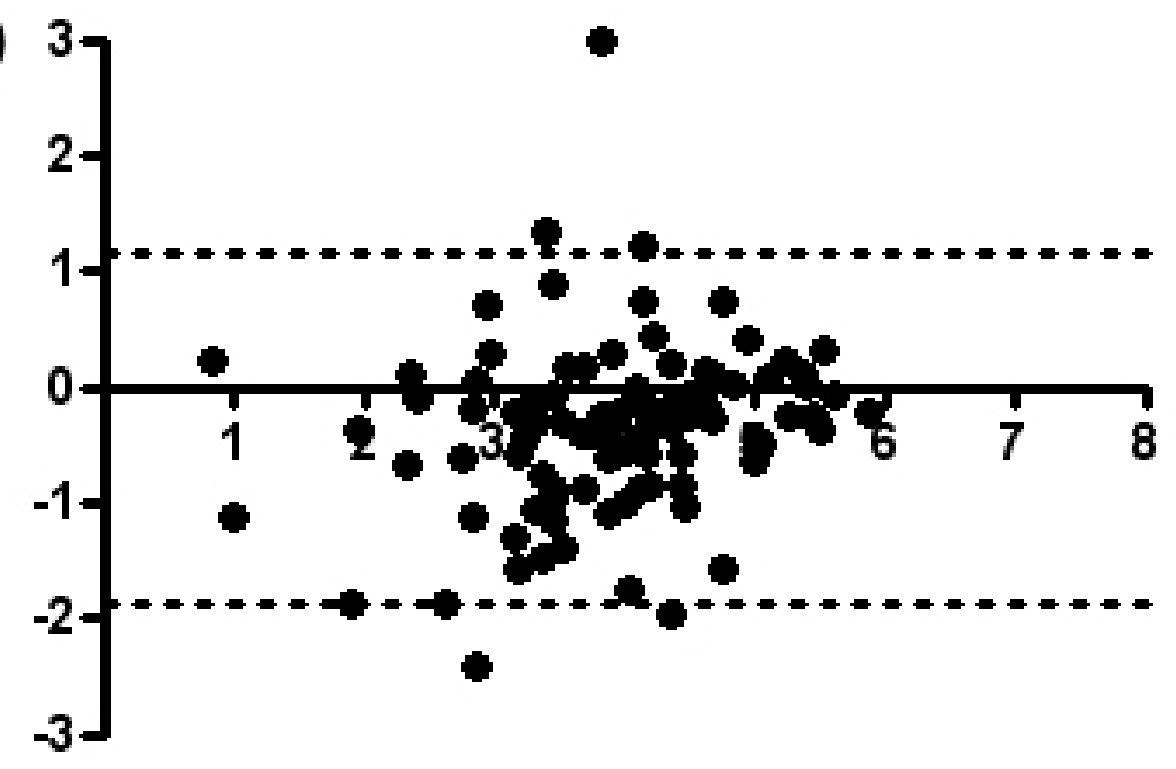

c)

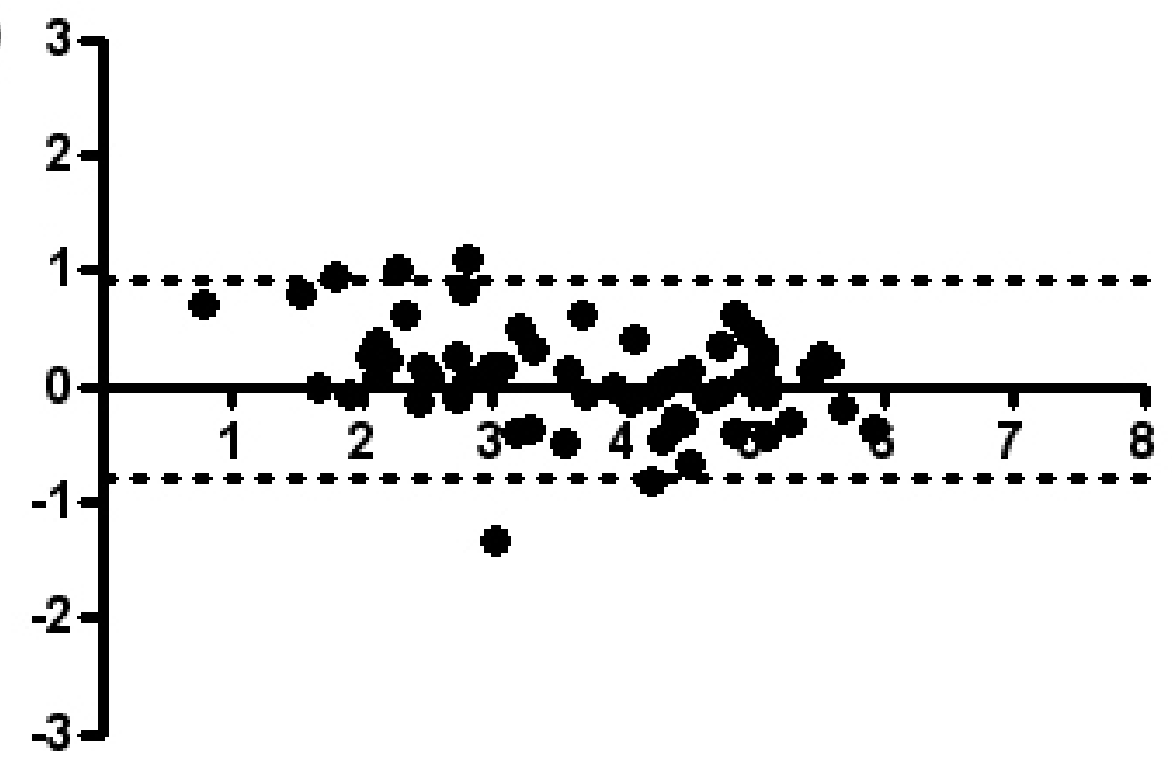

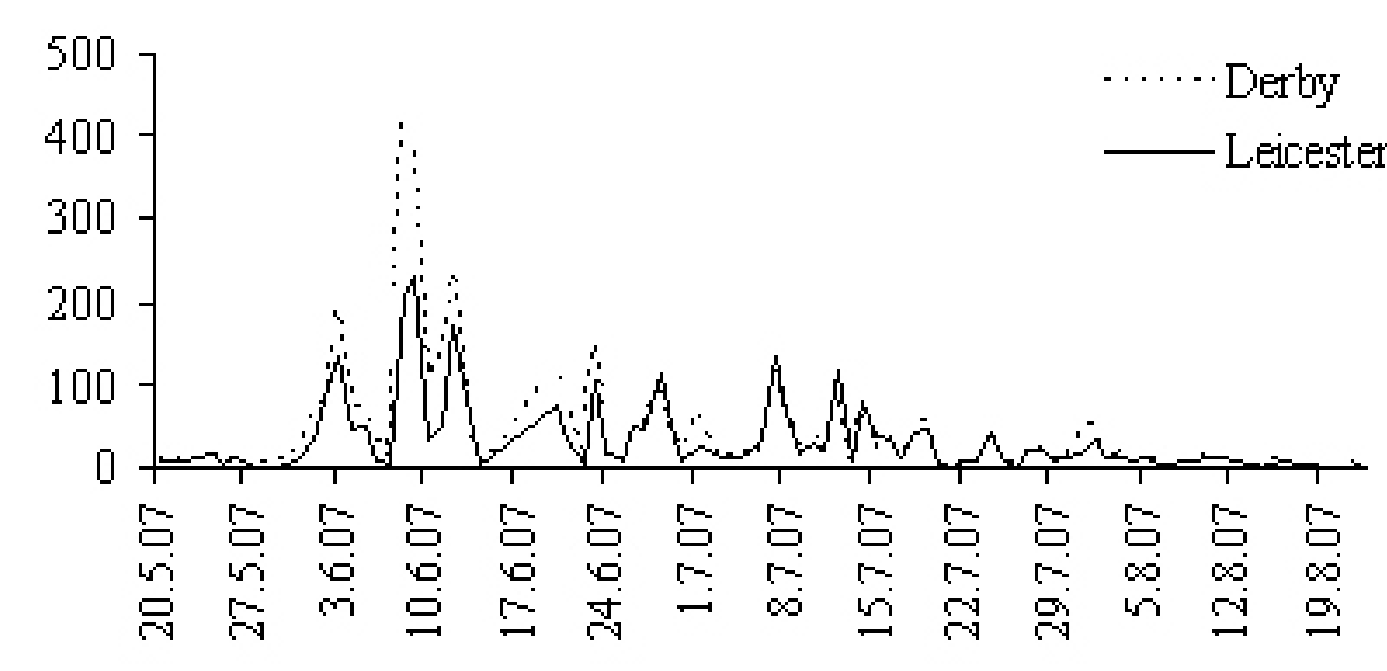
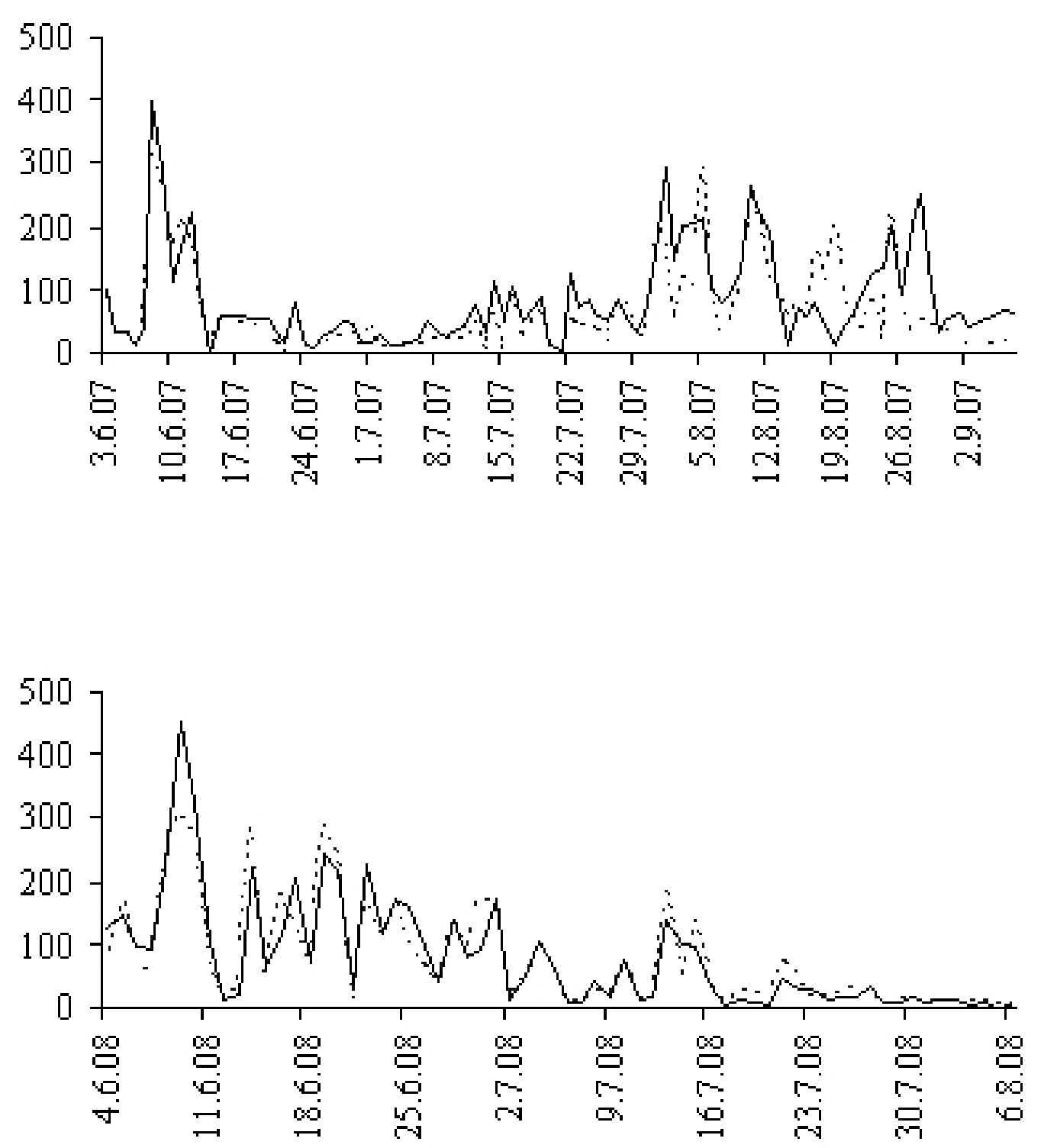

d)
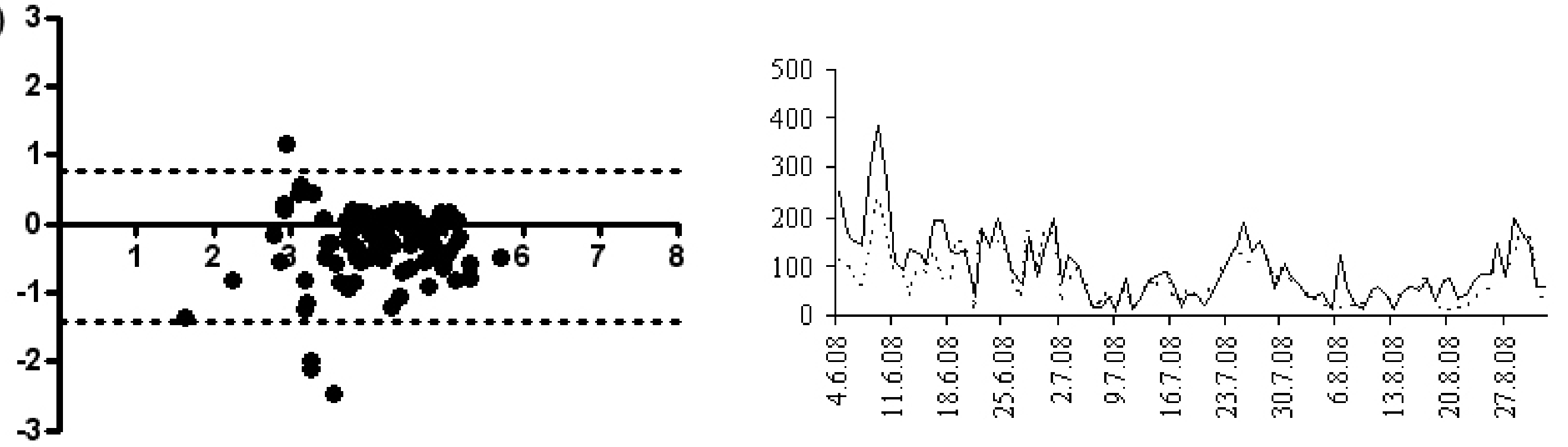